\title{
MAM-11 \\ COLD VAPOUR GENERATION ELECTROTHERMAL ATOMIC ABSORPTION \\ SPECTROMETRY AND SOLID PHASE EXTRACTION BASED ON A NEW NANOSORBENT FOR SENSITIVE HG DETERMINATION IN ENVIRONMENTAL SAMPLES (SEA WATER AND RIVER WATER)
}

\section{Elisa Vereda Alonso, $M^{a}$ Teresa Siles Cordero, $M^{a}$ del Mar López Guerrero, Amparo García de Torres and José Manuel Cano Pavón}

Department of Analytical Chemistry, Faculty of Sciences, University of Malaga, Campus de Teatinos, 29071, Málaga, Spain, email: eivereda@uma.es

Mercury is not an essential element for plant or animal life and it is a potential environmental toxic because of its tendency to form covalent bonds with organic molecules and the high stability of the $\mathrm{Hg}-\mathrm{C}$ bond. Reports estimate a total mercury concentration in natural waters ranging from 0.2 to $100 \mathrm{ng} \mathrm{L-1.} \mathrm{Due} \mathrm{to} \mathrm{this} \mathrm{fact,} \mathrm{highly}$ sensitive methods are required for direct determination of such extremely low levels. In this work, a rapid and simple method was developed for separation and preconcentration of mercury by flow injection solid phase extraction coupled with online chemical vapour generation electrothermal atomic absorption spectrometry. The system is based on chelating retention of the analyte onto the mini column filled with a mesoporous silica functionalized with 1,5 bis (di-2-pyridyl) methylene thiocarbohydrazide. The main aim of this work was to develop a precise and accurate method for the determination of the $\mathrm{Hg}$. Under the optima conditions and $120 \mathrm{~s}$ preconcentration time, the detection limit obtained was $0.009 \mu \mathrm{g} L-1$, with RSDs $3.7 \%$ for $0.2 \mu \mathrm{g} \mathrm{L}-1,4.8 \%$ for $1 \mu \mathrm{g} \mathrm{L-1}$ and enrichment factor 4, Furthermore, the method proposed has permitted the determination of $\mathrm{Hg}$ with a reduction in the analysis time, the sample throughput was about $18 \mathrm{~h}-1$, low consumption of reagents and sample volume.

The method was applied to the determination of $\mathrm{Hg}$ in sea water and river water. For the quality control of the analytical performance and the validation of the newly developed method, the analysis of two certified samples, TMDA 54.4 Fortified Lake, and LGC6187 River sediment was addressed. The results showed good agreement with the certified values.

Acknowledgements: The authors thank the Spanish Ministerio de Ciencia y Tecnología (MCyT project no. CTQ2013-44791-P) for supporting this study and also FEDER funds and Universidad de Málaga, Plan Propio 